\title{
THE COMPARISON OF THAI TOURISTS BEHAVIORS IN CHOOSING THAI BOARDING POINT SERVICES: CASE STUDY OF THAI- LAO BRIDGE, NONGKHAI AND NAKORN PANOM
}

\author{
Susaraporn Tangtenglam
}

\begin{abstract}
This study aims are (1) to investigate Thai tourists' behaviour of choosing border services in Nongkhai and Nakhon Phanom provinces (2) to study border services qualification in Nongkhai and Nakhon Phanom provinces (3) to compare the Thai tourists' goals of choosing border services in Nongkhai Border (NB) and Nakhon Phanom Border (NPB) and (4) to compare qualification of border services between Nongkhai Border (NB) and Nakhon Phanom Border (NPB).The questionnaire was used as a main research instrument. It was used to collect the data on the perception of the 770 samples. The samples are all Thai tourists and use border services from both Nongkhai Border (385) and Nakhon Phanom Border (385). The convenience sampling was used a main method of data analysis. The collected data was analysed by using statistical package. Frequency, Percentage, Mean, Standard Deviation, and ANOVA (i.e. t-test, F-test) were also used to analyse the collected data.
\end{abstract}

The results show that the Nakhon Phanom Border (NPB), most of the samples were 202 female tourists $(52.47 \%)$, aged between $31-40$ years. The samples were 155 tourists $(40.26 \%)$, and the samples who had Bachelor Degree were 186 (48.31\%). They approximately gained 25, 001 Bath for monthly income. The 117 samples (30.39\%) out of 297 samples (77.14\%) were students. The reason the border service at Nakhon Phanom Border (NPB) was for the trading purpose, showing 132 samples $(34.29 \%)$. The tourists perceived the service as moderate, representing 3.27 in percentage and 0.16 in standard deviation. For the income, it showed that there are some factors such as objective factor $(=3.87$, S.D. $=0.29)$, responsive factor $(=3.66$,S.D. $=0.33)$, trust $(=3.57$,S.D.= $0.32)$, knowing each other $(=2.80$, S.D. $=0.32)$ and warranty $(=2.44$, S.D. $=0.27)$. The results show that the Nongkhai Border (NB), most of the samples were 194 female tourists $(50.40 \%)$, aged between $31-40$ years. The samples were 187 tourists (48.60\%), and the samples who had Bachelor Degree were 195 (50.60\%). They approximately gained above 25, 001 Bath for monthly income. The 316 samples $(82.10 \%)$ out of 297 samples. The 113 samples $(29.40 \%)$ were traders. The reason the border service at Nongkhai Border (NB) was for the travelling purpose, showing 155 samples $(40.30 \%)$. The tourists perceived the service as high, ( = 3.76 ,S.D.=0.16). In this regard, it showed that there are some factors such as objective factor $(=4.02$,S.D. $=0.32)$, warranty $(=3.98$,S.D. $=$ $0.28)$, trust $(=3.87$, S.D. $=0.29)$, responsive factor $(=3.53$,S.D. $=0.29)$, knowing each other $(=$ 3.37, S.D.= 0.36).

It is suggested that the tourists who had different ages, education background, monthly income, and different purposes in travelling showed no difference at 0.05 in statistical difference in border service use in Nakhon Phanom Border. However, the factors i.e. age and occupation within the same group showed statistical difference at 0.05 in border service use in Nakhon Phanom Border. For Nongkai Border, the tourists who had different ages, education background, monthly income, and different purposes in travelling showed no difference at 0.05 in statistical difference in border service use in Nongkai Border. However, the factors i.e. age and occupation within the same group showed statistical difference at 0.05 in border service use in Nongkai Border.

Keywords: Thai-Lao Friendship Bridge, Tourists behaviors 


\section{INTRODUCTION}

Thailand and the Lao People's Democratic Republic's borders have been connected for a long time. It has been known that the two counties have been joining 'trade' and 'travel' for long time. It has also has an effect on transportation between these two countries and has been considered as 'Thai-Lao as neighbour' and have good relationships for long time including geography, society, culture and language, politic and economy, especially the transportation between Thai and Lao, travelling. Besides, with a 'history' that has been developed for long time, and with the closeness of Thailand and Lao. Their borders have been connected approximately 1.810 kilometres, and been connected to 11 provinces: Nong Khai, Mukdahan, Ubonrachathani, Nakhon Phanom, Loei, Nan, Phayao, Utaradit, Chaiangrai, Pitsanulok, and Umnartcharoen. It has passed through 'border trade' in 36 points as they are called ' 36 permanent border service point', 2 temporary border service points', and 20 negotiating points. The transportation from Thailand to Lao can be done by private car, train, or transportation cars. Thus, there is a potential for many Thai tourists to travel in Lao. This is also supported by Thailand and Lao governments, in particular 'transportation business between Thailand and Lao.

The people from the Greater Mekong Sub-region (GMS) countries such as Myanmar, Thailand, Cambodia, the People Republic of China, the Lao People's Democratic Republic and Vietnam are 240 million. They have their own identities in their society, and culture. From this reason, it has attracted the people to travel in GMS. In 1992, GMS countries have been offered helped from Asian Development Bank (ADB) to be able to cooperate in economic with the Greater Mekong Sub-region (GMS).

As above reasons, countries in this region tend to expand more trades into the region such as the Indonesia Malaysia Thailand Growth Triangle or IMT-GT, Great Mekong Basin Region or GSM comprising of 6 countries including China, Thailand, Myanmar, Vietnam, Laos and Cambodia. These economic cooperative groups have cooperated in trades, investments and transportation connection. Thailand has benefited from these kinds of cooperation to expand trade into the region as well as expanding tourism industry in the provinces along the inter-connected transportation routes. Thailand is geographical center of South East Asia as it has borders with neighboring countries. Thailand can trade with 4 neighboring countries including Myanmar, Laos, Malaysia and Cambodia which share the border lines with 30 provinces of Thailand. This can enhance different forms of trade.

In term of tourism, these economic areas can attract tourists to experience the natures and the exotic cultures, which spot all over the provinces along Mekong River. These include nature, history, culture, tradition, life style of different ethnic groups. The rich resources will help promote Thailand becoming tourist hub of the region or becoming Indochina Gateway.

The other benefit of Thai government's open boarding point service of bordering provinces along Myanmar, Malaysia, Laos, and Cambodia is that it boosts tourism in the area. The number of tourists has increased. This encourages the Thai government to promote tourism in boarding points. As a result, Thailand has cooperated with Australia and Laos to construct the bridge across the longest river in South East Asia (about 4,000 km) in Nongkhai province. This river flows through many countries including China, Myanmar, Laos, Thailand, Cambodia and Vietnam. It is the first bridge crossing Mekong River, connecting Thailand and Laos. The bridge is called Thai-Laos Friendship Bridge. The bridge connects the transportation from Nongkhai to Vientiane. Besides, Thailand has constructed the third bridge crossing Mekong River in Nakorn Panom, which connected Thailand with Kam Muan of Laos. The bridge enhances the traveling between Nongkhai and Nakorn Panom of Thailand and Kam Muan of Laos with comfort. As a result, it boosts Thai cargo transportation as well as tourism.

The geographical advantage of Nongkhai and Nakorn Panom as a gateway for trade, investment and tourism results in the changes in society, economy, trade, and tourism of both provinces. Moreover, the openness, political stability, natural resources of Laos 
supports the future forecast that there will be more development to support the economic and social growth as well as the growth in tourism. This will drive Thailand to become tourism hub in the Sub Mekong region or Indochina Gateway. These promising situations encouraged the researcher to conduct the research of The Comparision of Thai Tourists behaviors in choosing Thai boarding point services : Case study of Thai- Lao Bridge, Nongkhai and Nakorn Panom. The research aims to compare the tourist behavior in choosing boarding point services. The study result would identify the motivation, attitudes and behaviors which could be useful in tourism strategy to increase number of tourists in the provinces that have boarding point. The result of the study could be used to improve the service quality of the boarding points to meet the needs and satisfaction

\section{OBJECTIVES/RESEARCH QUESTIONS}

(1) To investigate Thai tourists' behaviour of choosing border services in Nongkhai and Nakhon Phanom provinces

(2) To study border services qualification in Nongkhai and Nakhon Phanom provinces (3) To compare the Thai tourists' goals of choosing border services in Nongkhai Border (NB) and Nakhon Phanom Border (NPB)

(4) To compare qualification of border services between Nongkhai Border (NB) and Nakhon Phanom Border (NPB).

\section{RESEARCH METHODOLOGY}

The questionnaire was used as a main research instrument. It was used to collect the data on the perception of the 770 samples. The samples are all Thai tourists and use border services from both Nongkhai Border (385) and Nakhon Phanom Border (385). The convenience sampling was used a main method of data analysis. The collected data was analysed by using statistical package. Frequency, Percentage, Mean, Standard Deviation, and ANOVA (i.e. t-test, F-test)

\section{FINDINGS}

Summary of tourists' opinion on quality of boarding point service Nakornpanom province

Tourists' opinion on the service quality is average ( $=$ 3.27 ,S.D.= 0.16). When considered each area of service, the result can be summarized from high to low as follows.

Tangibility aspect $(=3.87$, S.D. $=0.29)$ Response $(=$ 3.66 ,S.D. $=0.33)$ Trust $(=3.57$,S.D. $=0.32)$ Understanding ( = 2.80 ,S.D. $=0.32)$ and Guarantee ( $=2.44$,S.D. $=0.27$ )

\section{Nongkhai provice}

Tourists' opinion on the service quality is high ( = 3.76 ,S.D.= 0.16) When considered each area of service, the result can be summarized from high to low as follows.

Tangibility ( $=4.02$,S.D.= 0.32) Guarantee ( = 3.98,S.D. $=0.28)$ Trust $(=3.87$, S.D. $=0.29)$ Response $(=3.53$, S.D. $=0.29)$ and understanding $(=$ 3.37,S.D. $=0.36)$

\section{SUMMARY RESULTS ACCORDING TO THE RESEARCH HYPOTHESIS}

1.The behaviors in choosing boarding point in Nakorn Panom of tourists with different genders in terms of response, understanding, tangibility have no differences with significant statistic at 0.05. The behaviors in choosing boarding point in Nakorn Panom of tourists with different genders in terms of trust and guarantee are different with significant statistic at 0.05

2.The behaviors in choosing boarding point in Nakorn Panom of tourists with different ages in terms of response, guarantee, and tangibility have no differences with significant statistic at 0.05. The behaviors in choosing boarding point in Nakorn Panom of tourists with different ages in terms of trust and understanding are different with significant statistic at 0.05

3.The behaviors in choosing boarding point in Nakorn Panom of tourists with different education 
backgrounds in all aspects are different with significant statistic of 0.05

4.The behaviors in choosing boarding point in Nakorn Panom of tourists with different average incomes in terms of understanding, guarantee and tangibility have no differences with significant statistic of 0.05 . The behaviors in choosing boarding point in Nakorn Panom of tourists with different average incomes in terms of trust and response are different with significant statistic of 0.05

5.The behaviors in choosing boarding point in Nakorn Panom of tourists with different careers in terms of response and tangibility have no differences with significant statistic of 0.05 . The behaviors in choosing boarding point in Nakorn Panom of tourists with different careers in terms of trust, understanding and guarantee are different with significant statistic of 0.05

6.The behaviors in choosing boarding point in Nakorn Panom of tourists with different traveling objectives in terms of response, understanding, and tangibility have no differences with significant statistic of 0.05 . The behaviors in choosing boarding point in Nakorn Panom of tourists with different traveling objectives in terms of trust and guarantee are different with significant statistic at 0.05 Nongkhai boarding point

1.The behaviors in choosing boarding point in Nongkhai of tourists with different

genders in terms of trust, understanding, tangibility and guarantee have no differences with significant statistic of 0.05 . The behaviors in choosing boarding point in Nongkhai of tourists with different genders in terms of response are different with significant statistic of 0.05 .

2.The behaviors in choosing boarding point in Nongkhai of tourists with different ages in terms of trust, guarantee, and tangibility have no differences with significant statistic of 0.05 . The behaviors in choosing boarding point in Nongkhai of tourists with different ages in terms of response and understanding are different with significant statistic of 0.05

3.The behaviors in choosing boarding point in Nongkhai of tourists with different education backgrounds in terms of trust, response and guarantee have no difference with significant statistic of 0.05 . The behaviors in choosing boarding point in Nongkhai of tourists with different education backgrounds in terms of understanding and tangibility are different with significant statistic of 0.05 .

4.The behaviors in choosing boarding point in Nongkhai of tourists with different average incomes in terms of guarantee and trust have no differences with significant statistic of 0.05 . The behaviors in choosing boarding point in Nongkhai of tourists with different average incomes in terms of response, understanding and tangibility are different with significant statistic of 0.05

5.The behaviors in choosing boarding point in Nongkhai of tourists with different careers in terms of trust and tangibility have no differences with significant statistic of 0.05 . The behaviors in choosing boarding point in Nongkhai of tourists with different careers in terms of response, understanding and guarantee are different with significant statistic of 0.05

6.The behaviors in choosing boarding point in Nongkhai of tourists with different traveling objectives in terms of response and guarantee has no differences with significant statistic of 0.05 . The behaviors in choosing boarding point in Nongkhai of tourists with different traveling objectives in terms of trust, understanding and tangiblity are different with significant statistic at 0.05

\section{DISCUSSIONS}

1. Comparison of Thai tourist opinion on service quality of Thai boarding point : Case study of ThaiLao friendship bridge in Nakorn Panom with different ages, genders, educations, average incomes, careers and traveling objectives.

Tourists with different genders, educations, average incomes and traveling objectives have no behavioral different in choosing boarding point in Nakorn Panom, with significant statistic of 0.05 . The results are in line with the study of Anothai Mahamart et al.(2012), who studied the guidelines for potential and strategy development of service quality of Taksila Hotel, Tambol Talad, Mahasarakam province. 
He found that the hotel's clients with different ages, genders, educations, and incomes have the similar opinion on service quality of the hotel with significant statistic of 0.05 .

2. Comparison of Thai tourist opinion on service quality of Thai boarding point : Case study of ThaiLao friendship bridge in Nongkhai with different ages, genders, educations, average incomes, careers and traveling objectives.

Tourists with different genders, educations, average incomes and traveling objectives have no behavioral different in choosing boarding point in Nongkhai, with significant statistic of 0.05 . The results are in line with the study of Anothai Mahamart et al. (2012), who studied the guidelines for potential and strategy development of service quality of Taksila Hotel, Tambol Talad, Mahasarakam province. He found that the hotel's clients with different ages, genders, educations, and incomes have the similar opinion on service quality of the hotel with significant statistic of 0.05 .

\section{RECOMMENDATIONS}

1. The scope of the study should focus on the service marketing strategy in order to improve service to response to the need of tourists.

2. The scope of the research content should include the study of the potential in officer performance development of both Nakornpanom and Nongkhai provinces in order to improve their performance.

\section{RESEARCH LIMITATION}

The researcher conducted the research under the title of The Comparison of Thai Tourists Behaviors in Choosing Thai Boarding Pont Services : Case Study of Thai-Lao Bridge, Nongkhai and Nakorn Panom 2012. The researcher found some limitations of data gathering, which can be summarized as follows:

\section{REFERENCES}

Hoffman, K. D., \& Bateson, J. E. G. (2006). Services marketing: Concepts, strategies, \& Cases.

Mason, OH: Thomson South-Western.Millet, J. D. (1954). Management in the public service. New York: McGraw-Hill. 